\title{
Optimum nitride concentration in multiband III-N-V alloys for high efficiency ideal solar cells
}

\author{
E. Cánovas, ${ }^{1, a)}$ A. Martí, ${ }^{1}$ A. Luque, ${ }^{1}$ and W. Walukiewicz ${ }^{2}$ \\ ${ }^{1}$ Instituto de Energía Solar, Universidad Politécnica de Madrid, Madrid 28040, Spain \\ ${ }^{2}$ Materials Sciences Division, Lawrence Berkeley National Laboratory, Berkeley 94720, California, USA
}

(Received 15 April 2008; accepted 6 October 2008; published online 31 October 2008)

\begin{abstract}
III- $\mathrm{N}_{x}-\mathrm{V}_{1-x}$ highly mismatched alloys (HMAs) have been proposed as promising material candidates for the development of high efficiency solar cells. According to the band anticrossing model, these alloys present a multiband character with an intermediate band within the otherwise fundamental bandgap that gives them the ability of improving the efficiency by means of below-bandgap photon absorption. The efficiency of $\mathrm{GaN}_{x} \mathrm{As}_{1-x}, \mathrm{GaN}_{x} \mathrm{P}_{1-x}$, and their quaternaries $\mathrm{In}_{y} \mathrm{Ga}_{1-y} \mathrm{~N}_{x} \mathrm{As}_{1-x}$ and $\mathrm{GaN}_{x} \mathrm{P}_{1-x-y} \mathrm{As}_{y}$ is estimated theoretically versus nitrogen content in this letter. Low nitrogen content in the range of $1 \%-3.5 \%$ in the HMAs analyzed leads to theoretical efficiencies above 60\%. () 2008 American Institute of Physics. [DOI: 10.1063/1.3013570]
\end{abstract}

Intermediate band (IB) solar cells have been proposed in order to substantially increase the efficiency of solar cells. A limiting efficiency as high as $63.2 \%$ has been predicted for these solar cells, ${ }^{1,2}$ which represents a higher figure than the one predicted for a tandem of two cells $(55.4 \%)$ and single gap solar cells $(40.7 \%)$.

The IB concept is based on having a band within the otherwise conventional bandgap of a semiconductor (Fig. 1). Thanks to the presence of this band, an IB material is able to absorb photons not only from the valence band (VB) to the conduction band (CB) but also from the VB to the IB and from the IB to the CB. This below-bandgap photon absorption is at the origin of the higher efficiency.

Three quasi-Fermi levels $\left(\varepsilon_{F, \mathrm{CB}}, \boldsymbol{\varepsilon}_{F, \mathrm{VB}}\right.$, and $\left.\varepsilon_{F, \mathrm{IB}}\right)$ coexist in the IB material each related to the carrier population in each of the three bands involved (Fig. 1). In order to preserve the output voltage $\left(q V=\varepsilon_{F, \mathrm{CB}}-\varepsilon_{F, \mathrm{VB}}\right)$ of the solar cell, the IB must be electrically isolated from the contacts.

To calculate the maximum efficiency, the IB model also assumes ideal photon absorption selectivity and that all the recombination processes between bands are radiative. Ideal photon absorption selectivity implies ${ }^{3}$ that a photon of a given energy $\varepsilon$ can only be absorbed through transition from the VB to the $\mathrm{CB}$, from the VB to the IB or from the IB to the CB denoted by $A_{\mathrm{VB} \rightarrow \mathrm{CB}}, A_{\mathrm{VB} \rightarrow \mathrm{IB}}$ or $A_{\mathrm{IB} \rightarrow \mathrm{CB}}$ in Fig. 1 . Ideal photon selectivity causes that the limiting case in which the IB is located exactly at the gap center produces no effect in the cell performance. On one hand, this is due to the fact that with the IB located exactly at the gap center, the absorption of below-bandgap energy photons do not lead to the generation of a net electron hole in the CB and VB (because if, for example, transition $A_{\mathrm{VB} \rightarrow \mathrm{IB}}$ is possible then, $A_{\mathrm{IB} \rightarrow \mathrm{CB}}$ is not). On the other hand, due to detailed balance, it does not introduce either a radiative recombination path between the $\mathrm{CB}$ and VB. A detailed description of additional properties and constrains for IB materials and solar cells can be found elsewhere. ${ }^{1,2,4}$

The published results concerning IB materials that involve experimental work are related to the use of quantum dot (QD) nanostructures and III- $\mathrm{N}_{x}-\mathrm{V}_{1-x}$ highly mismatched alloys (HMAs). The QD approach ${ }^{5}$ has proven some basics of the theory, including the coexistence of three quasi-Fermi levels ${ }^{6-8}$ and the extraction of photocurrent from the IB $\rightarrow$ CB transition due to below-bandgap photon absorption. ${ }^{9}$

On the other hand, a good quality HMA IB material has been synthesized ${ }^{10}$ by nitrogen ion implantation followed by a combination of rapid thermal annealing and pulse laser melting. The origin of the IB in HMAs such as III- $\mathrm{N}_{x}-\mathrm{V}_{1-x}$ has been explained by the two-level band anticrossing mode $^{11}$ (BAC) as a splitting of the CB due to the presence of a related nitrogen resonant impurity level above the $\mathrm{CB}$ of the III-V host semiconductor matrix. The BAC model explains properly the experimentally observed composition and pressure dependencies of the bands in III- $\mathrm{N}_{x}-\mathrm{V}_{1-x}$ alloys ${ }^{12}$ and has predicted several related effects such as the enhancement of the electron effective mass ${ }^{13}$ and the improvement of donor activation efficiency. ${ }^{14}$

A practical and useful aspect of the QD and HMA approaches is that the position of the IB can be tuned in order to get the ideal optimum efficiency. For the QD approach, it can be made by tailoring the size of the nanostructures forming the IB material, ${ }^{15}$ whereas for the nitride alloy approach, the IB position within the bandgap is dependent on the ni-

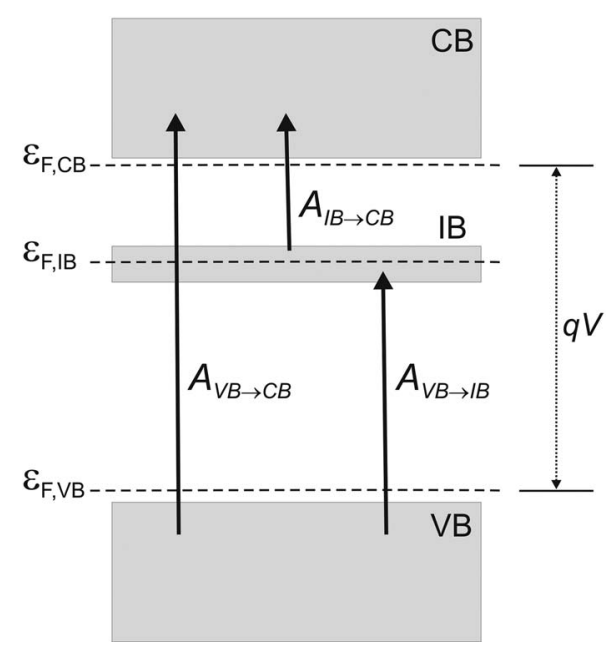

FIG. 1. Simplified band diagram of a solar cell with an IB 

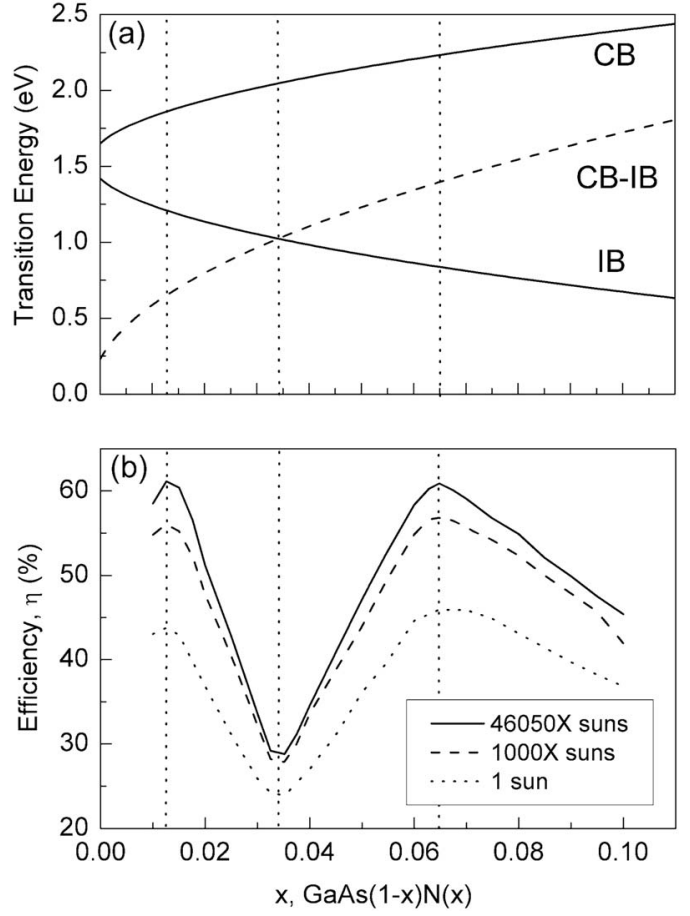

FIG. 2. (a) Main transition energies predicted by the BAC as a function of nitrogen content in $\mathrm{GaN}_{x} \mathrm{As}_{1-x}$. (b) Ideal efficiency curves as a function of nitrogen content in $\mathrm{GaN}_{x} \mathrm{As}_{1-x}$ for different light concentrations.

trogen content. ${ }^{12}$ In this letter, we will analyze the optimum nitrogen content in several diluted III- $\mathrm{N}_{x}-\mathrm{V}_{1-x}$ alloys required to reach the maximum photovoltaic conversion efficiency. The conditions and procedure for the estimations of the efficiencies that we will assume in this letter have been described in detail in Ref. 1.

According to the BAC model, the newly formed subbands due to the nitrogen presence in the alloy named $E+$ and $E-(\mathrm{CB}$ and $\mathrm{IB}$, respectively) have energy dispersion relations given by

$$
E_{ \pm}(k)=\frac{1}{2}\left\{\left[E^{C}(k)+E^{L}\right] \pm \sqrt{\left[E^{C}(k)-E^{L}\right]^{2}+4 V^{2} x}\right\},
$$

where $E^{C}(k)$ is the energy dispersion of the lowest related $\mathrm{CB}$ of the host matrix, and $E^{L}$ is the energy of the localized states derived from the substitutional $\mathrm{N}$ atoms. $V$ describes the coupling between the localized states and the band states of the host, and $x$ is the nitrogen concentration in the alloy $(x \in[0,1])$.

Among the different III- $\mathrm{N}_{x}-\mathrm{V}_{1-x}$ HMAs that have been reported having a multiband character we will focus our attention in the ternaries $\mathrm{GaN}_{x} \mathrm{As}_{1-x}$ and $\mathrm{GaN}_{x} \mathrm{P}_{1-x}$ and their quaternaries $\operatorname{In}_{y} \mathrm{Ga}_{1-y} \mathrm{~N}_{x} \mathrm{As}_{1-x}$ and $\mathrm{GaN}_{x} \mathrm{P}_{1-x-y} \mathrm{As}_{y}$. Adding In to $\mathrm{GaN}_{x} \mathrm{As}_{1-x}$ or As to $\mathrm{GaN}_{x} \mathrm{P}_{1-x}$ allows for lattice matching and defect free epitaxial growth on readily available substrates. Thus $\mathrm{In}_{y} \mathrm{Ga}_{1-y} \mathrm{~N}_{x} \mathrm{As}_{1-x}$ can be lattice matched to GaAs (for $y \sim 3 x$ ) or germanium. It can be also lattice matched to $\mathrm{Al}_{y} \mathrm{Ga}_{1-y} \mathrm{As}$, which is probably the best candidate for the $p$ and $n$ emitters sandwiching the IB material. On the other hand $\mathrm{GaN}_{x} \mathrm{P}_{1-x-y} \mathrm{As}_{y}$ can be lattice matched to silicon.

Figure 2(a) shows the BAC theoretical dispersion relations for $\mathrm{GaN}_{x} \mathrm{As}_{1-x}$ as a function of the nitrogen content given by Eq. (1) at room temperature. For this particular alloy $E^{C}(k)=1.42 \mathrm{eV}, E^{L}=1.65 \mathrm{eV}$, and the coupling parameter $V=2.7$ according to experimental data fitting process. ${ }^{12}$ Figure 2 (b) shows the efficiency estimated according to the model presented in Ref. 1 for $\mathrm{GaN}_{x} \mathrm{As}_{1-x}$ as a function of nitrogen content. The plot shows ideal (radiative limit) efficiency estimations for the IB material considered operating under $1 \times, 1000 \times$, and $46050 \times$ suns of light concentration. Notice the presence of two close maxima of efficiency in the nitrogen content range analyzed in this work $(x \in[0,0.1])$. The maximum efficiency $61.1 \%$, is obtained for a nitrogen content of $1.25 \%$. It also represents the best scenario attending practical aspects because at present, only good quality samples have been developed for diluted III- $\mathrm{N}_{x}-\mathrm{V}_{1-x}$ HMAs.

Table I lists the optimum nitrogen content, transition energies, and maximum ideal efficiencies for the selected III- $\mathrm{N}_{x}-\mathrm{V}_{1-x}$ HMAs analyzed in this letter. The values for $E^{C}(k), E^{L}$, and the coupling parameter $V$ for the different analyzed alloys can be found in the literature. ${ }^{12,16-18}$ Nitrogen contents leading to the location of the IB at the gap center and minimum efficiency when photon selectivity is considered are also given in Table I.

In summary, we have calculated the optimum nitrogen content in order to obtain the maximum ideal efficiency in selected III- $\mathrm{N}_{x}-\mathrm{V}_{1-x}$ HMAs according to the ideal IB solar cell theory. Low nitrogen content in the range of $1 \%-3.5 \%$ in the HMAs analyzed can conduce to efficiencies over $60 \%$ for most of the cases. Finally, it must be remembered that the calculations refer to the radiative limiting efficiency. Practi-

TABLE I. Optimum nitrogen content and transition energies for maximum ideal efficiencies in selected III- $\mathrm{N}_{x}-\mathrm{V}_{1-x}$ HMAs. The efficiency and corresponding $\mathrm{N}$ content obtained when the IB is located just in the midpoint of the wider bandgap are also presented (lower row for each compound in the table).

\begin{tabular}{lccccc}
\hline \hline Sample & $\begin{array}{c}\text { N content } \\
x\end{array}$ & $\begin{array}{c}\text { Efficiency at } \\
1000 \text { suns } \\
(\%)\end{array}$ & $\begin{array}{c}\text { Efficiency at } \\
46050 \text { suns } \\
(\%)\end{array}$ & $\begin{array}{c}\text { VB } \rightarrow \mathrm{CB} \\
\text { transition } \\
\text { energy } \\
(\mathrm{eV})\end{array}$ & $\begin{array}{c}\mathrm{VB} \rightarrow \mathrm{IB} \\
\text { transition } \\
\text { energy } \\
(\mathrm{eV})\end{array}$ \\
\hline & 1.25 & 56.0 & 61.1 & 1.85 & 1.21 \\
$\mathrm{GaN}_{x} \mathrm{As}_{1-x}$ & 3.41 & 26.5 & 28.0 & 2.04 & 1.02 \\
$\mathrm{GaN}_{x} \mathrm{P}_{1-x}$ & 3.21 & 50.5 & 53.7 & 3.09 & 1.83 \\
$\mathrm{In}_{3 x} \mathrm{Ga}_{1-3 x} \mathrm{~N}_{x} \mathrm{As}_{1-x}$ & 6.18 & 7.6 & 8.7 & 3.28 & 1.64 \\
$\mathrm{GaN}_{x} \mathrm{As}_{1-x-0.4} \mathrm{P}_{0.4}$ & 1.21 & 56.0 & 61.7 & 1.83 & 0.65 \\
\hline \hline
\end{tabular}


cal efficiencies will be lower when considering nonideality effects such as nonradiative recombination and a higher temperature of operation for the solar cell.

This work has been supported by the European Commission within the project IBPOWER (Contract No. 211640) and the projects NUMANCIA (Contract No. S-0505/ENE/ 000310) funded by the Comunidad de Madrid and GENESIS-FV (Contract No. CSD2006-00004) funded by the Spanish National Programme. E.C. acknowledges the "Plan Nacional de Formación de Personal Investigador" research grant.

${ }^{1}$ A. Luque and A. Martí, Phys. Rev. Lett. 78, 5014 (1997).

${ }^{2}$ A. Luque and A. Martí, Prog. Photovoltaics 9, 73 (2001).

${ }^{3}$ A. S. Brown and M. A. Green, J. Appl. Phys. 92, 1329 (2002).

${ }^{4}$ L. Cuadra, A. Martí, and A. Luque, IEEE Trans. Electron Devices 51, 1002 (2004).

${ }^{5}$ A. Martí, N. López, E. Antolín, E. Cánovas, C. Stanley, C. Farmer, L. Cuadra, and A. Luque, Thin Solid Films 511, 638 (2006).

${ }^{6}$ A. Luque, A. Marti, C. Stanley, N. Lopez, L. Cuadra, D. Zhou, J. L. Pearson, and A. McKee, J. Appl. Phys. 96, 903 (2004).

${ }^{7}$ A. Luque, A. Marti, N. Lopez, E. Antolin, E. Canovas, C. Stanley, C. Farmer, L. J. Caballero, L. Cuadra, and J. L. Balenzategui, Appl. Phys. Lett. 87, 083505 (2005).

${ }^{8}$ A. Luque, A. Martí, N. López, E. Antolín, E. Cánovas, C. R. Stanley, C.
Farmer, and P. Díaz, J. Appl. Phys. 99, 094503 (2006).

${ }^{9}$ A. Martí, E. Antolin, C. R. Stanley, C. D. Farmer, N. Lopez, P. Diaz, E. Canovas, P. G. Linares, and A. Luque, Phys. Rev. Lett. 97, 247701 (2006).

${ }^{10}$ K. M. Yu, W. Walukiewicz, M. A. Scarpulla, O. D. Dubon, J. Wu, J. Jasinski, Z. Liliental-Weber, J. W. Beeman, M. R. Pillai, and M. J. Aziz, J. Appl. Phys. 94, 1043 (2003).

${ }^{11}$ W. Shan, W. Walukiewicz, J. W. Ager III, E. E. Haller, J. F. Geisz, D. J. Friedman, J. M. Olson, and S. R. Kurtz, Phys. Rev. Lett. 82, 1221 (1999).

${ }^{12}$ J. Wu, W. Shan, and W. Walukiewicz, Semicond. Sci. Technol. 17, 860 (2002).

${ }^{13}$ C. Skierbiszewski, P. Perlin, P. Wišniewski, W. Knap, T. Suski, W. Walukiewicz, W. Shan, K. M. Yu, J. W. Ager, E. E. Haller, J. F. Geisz, and J. M. Olson, Appl. Phys. Lett. 76, 2409 (2000).

${ }^{14}$ K. M. Yu, W. Walukiewicz, W. Shan, J. W. Ager III, J. Wu, E. E. Haller, J. F. Geisz, D. J. Friedman, J. M. Olson, and S. R. Kurtz, Phys. Rev. B 61, R13337 (2000).

${ }^{15}$ A. Marti, L. Cuadra, and A. Luque, Proceedings of the 28th IEEE Photovoltaic Specialists Conference, 2000 (unpublished), p. 940.

${ }^{16}$ J. Wu, W. Walukiewicz, K. M. Yu, J. W. Ager III, E. E. Haller, Y. G. Hong, H. P. Xin, and C. W. Tu, Phys. Rev. B 65, R241303 (2002).

${ }^{17}$ C. Skierbiszewski, P. Perlin, P. Wisniewski, T. Suski, J. F. Geisz, K. Hingerl, W. Jantsch, D. E. Mars, and W. Walukiewicz, Phys. Rev. B 65, 035207 (2001).

${ }^{18}$ K. M. Yu, W. Walukiewicz, J. Ager III, D. Bour, R. Farschi, O. D. Dubon, S. X. Li, I. D. Sharp, and E. E. Haller, Appl. Phys. Lett. 88, 092110 (2006). 